\title{
Cytogenetic Analysis of Radiotherapeutic and Diagnostic Workers Occupationally Exposed to Radiations
}

\author{
P. K. Gadhia, Nehal Shah, Sweta Nahata, Swati Patel, Krupa Patel, \\ Meonis Pithawala and Dipesh Tamakuwala
}

\author{
Department of Biosciences, South Gujarat University, Surat 395 007, Gujarat, India
}

KEYWORDS Radiation workers; human chromosomes; CAs; SCE; micronuclei

\begin{abstract}
The study group comprised of 12 occupationally exposed "radiotherapeutic and diagnostic workers", working since last 12 years on an average (service duration 3 to 20 years), with 12 age and sex-matched controls not exposed to any kind of radiation and belonging to same socio-economic status as the radiation workers. Cytogenetic end points studied were CAs (Chromosomal aberrations), SCE (Sister chromatid exchange) and MN (Micronuclei). Hematological parameters were also studied. In addition, co-mutagenic/synergistic in vitro effects of known mutagen Mitomycin-C (MMC) on lymphocytes of these workers were evaluated. Results revealed a significant increase in dicentric $(\mathrm{P}<0.05)$ as well as $\mathrm{MN}(\mathrm{P}<0.01)$ among radiation exposed workers when compared to controls. By contrast, no change in SCE frequencies and hematological parameters were observed. After in vitro MMC treatment CA (mainly dicentric and ring) increased significantly in lymphocytes of radiation exposed workers. Based on these observations, a preliminary indication of the study could be that long term low level radiation exposure may probably damage the genetic constitution of an individual.
\end{abstract}

\section{INTRODUCTION}

With development of techniques in cytogenetics, the response of human chromosomes to ionizing radiations both, in vivo and in vitro has been investigated thoroughly. In vitro studies on human lymphocytes exposed to different type of radiations have shown that, the frequency of induced aberrations are same as if they were exposed in vivo ((Evans 1983; Fabry and Lemaire 1986)

In vivo cytogenetic studies of accidental exposure of human to radiations have been carried out and are confined to groups like people exposed to Chernobyl explosion (Schevchekno et al. 1996; OSH-DB, 1996) radiation accident in Goiania-Brazil (Natarajan et al. 1991) Cobalt-60 accident at Zagreb (Milkovic-Kraus et al. 1992). Most, but not all have reported elevated levels of chromosomal aberrations.

Cytogenetic studies on individuals occupationally exposed to radiation have been carried out extensively. High frequency of CA such as dicentrics, rings and acentrics in the peripheral blood lymphocytes of personnel handling diagnostic X-ray machines has been reported by Jha and Sharma (1991) and Kasuba et al. (1998). Similarly Hagelstrom et al. (1995) reported a four fold increase in the incidence of $\mathrm{CA}$ in the peripheral lymphocytes of workers occupationally exposed to X-rays and nuclear medicine areas.

However, Lloyd et al. (2001) using both conventional as well as FISH analysis showed no significant difference between Namibian Uranium miner and controls in the frequencies of chromosome or chromatid type aberrations as well as the translocations. Similarly Cigarran et al. (2001) employing FISH analysis reported no significant difference in the frequencies of chromosomal abnormalities among hospital workers occupationally exposed to low level of radiations and the matched control groups.

With three colour fluorescence in situ suppression hybridization technique, Verdorfer et al. (2001) reported no significant difference in the frequencies of breaks among medical radiation appliers and the controls. However, breast tumor patients and military waste disposers showed a higher rate of aberrations than did the healthy controls. In the same study the authors reported that chromosome \# 4 was slightly over effected while chromosome \# 2 was slightly under represented. Pressl and Stephan (1998) conducted a study on X -ray diagnostic and $X$-ray therapeutic radiation workers, and concluded that dicentrics measured shortly after exposure was more sensitive indicator than translocations determined years latter using FISH 
technique.

Despite all these studies there is paucity of information on the cytogenetic changes among occupationally exposed radiation workers engaged for a long term in diagnostic and therapeutic applications of radiation. Hence, present study was carried out to evaluate the genetic damage with three cytogenetic end points namely CAs, SCE as well as MN among radiation workers whose service duration ranged from 3 to 20 years.

\section{MATERIALS AND METHOD}

Blood samples were collected in sodium heparinised vaccutainer tubes through veni puncture from twelve occupationally exposed radiotherapeutic and diagnostic workers working since last 12 years on an average. The particulars of each radiation workers involved in the study has been presented in Table 1, with respect to their age, sex, occupational category, duration of involvement in occupation, occasions for radiation exposure and its duration in hours per week, personal habits and addiction if any, health status at the time of blood collection etc. Twelve healthy age and sex matched individuals identical to the radiation workers in every respect but not exposed to any kind of radiation served as controls.

Routine peripheral blood lymphocyte culture technique of Hungerford (1965) was adopted with some modifications (Gadhia 1998). Four separate culture vials were set up from each individuals (radiation workers as well as controls); one for $\mathrm{CA}$, one for SCE and one for MN. In the remaining $10 \mathrm{ng} / \mathrm{m} 1$ of MMC was added after 24hours of initiation of culture. Cultures were terminated at 72 hours. A brief hypotonic treatment of $0.075 \mathrm{M} \mathrm{KCl}$ was given and the cells were fixed in 3:1 methanol acetic acid and airdried preparations were made.

Sister chromatid exchange (SCE) analysis was carried out by adding $10 \mu \mathrm{g} / \mathrm{ml}$ BudR to the culture at 24-hours of initiation. After air-dried preparations the slides were stained with Hoechst 33258, exposed to fluorescence light overnight, and then treated with $2 \mathrm{X} \mathrm{SSC}$ for one hour at $60^{\circ} \mathrm{C}$. Finally the slides were stained in $7 \%$ Giemsa.

For Micronuclei study, cytokinesis block method of Fenech (1993) was adopted with some modifications. At 44-hour, $0.6 \mu \mathrm{g} / \mathrm{ml}$ of cytochalasin-B (Sigma) was added and cultures were terminated at 72 hours. A brief treatment of chilled $0.75 \mathrm{M} \mathrm{KCl}$ was given. The cells were then spun and fixed in 3:1 methanol acetic acid. Air dried preparations were made. The slides were stained in May and Grunwald's stain $(0.25 \%$ w/v in methanol) for about 10 minutes and then counterstained with Giemsa.

One hundred well spread first division (M1) metaphases were scored for chromosomal aberrations. Each slides were blind coded and scored randomized to avoid observers bias. With

Table 1: Particulars of each radiotherapeutic and diagnostic workers studied cytogenetically

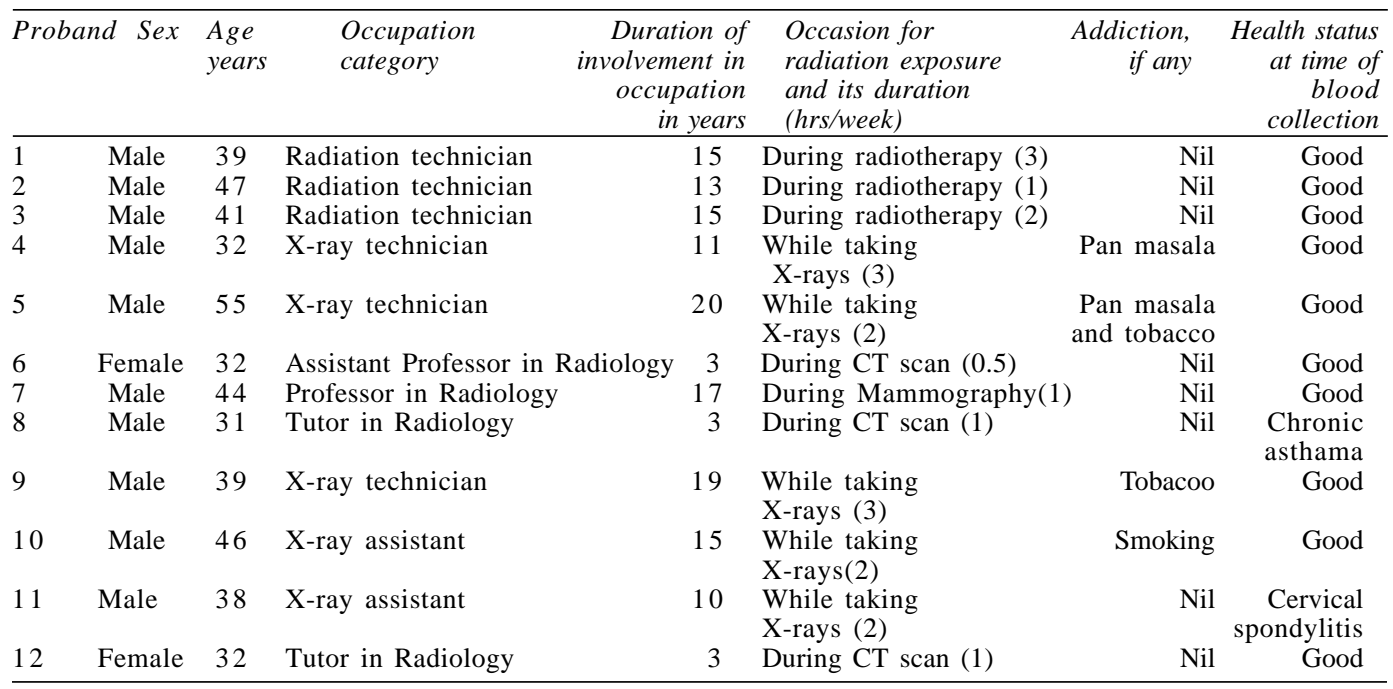


regard to SCE analysis, 30 well spread second division metaphase (M2) were scored. The replicative index $(\mathrm{RI})$ was calculated by considering percentage of Ml, M2 and M3 cells. About 1000 binucleated cells from each individual were counted for MN study.

For hematological analysis, blood samples were collected into EDTA bulbs. Automatic electronic blood cells counter (Erma, Japan) model PCE 170 was employed to analyse the sample. However while computing the table,only four major parameters (Total WBC, Total RBC, Total platelet counts and hemoglobin percentage) has been considered.

Statistical analysis of the results were done employing two tailed Student's 't' test.

\section{RESULTS}

The data on chromosomal aberrations among radiation workers and control groups with and without MMC treatment have been presented in Table 2.

Results revealed a significant increase in dicentric $(\mathrm{P}<0.05)$ and chromatid gaps $(\mathrm{p}<0.05)$ among the chromosomes of the radiation workers when compared to controls. After MMC treatment there was significant increase in dicentric $(P<0.05)$ as well as ring $(P<0.05)$ chromosomes among radiation workers as compared to MMC treated controls.

Results on the SCE frequency and MN study have been compiled in Table 3. No significant change in either mean SCE frequency or replicative index of radiation workers as well as controls was noticed. However MN frequency was statistically significant $(\mathrm{P}<0.01)$ among radiation workers as compared to control individuals.

An analysis of hematological parameters (Total WBC, Total RBC, Total platelet count, as well as hemoglobin percentage) pooled from twelve individuals did not show much variation as compared to control (Table 4).

\section{DISCUSSION}

The purpose of this investigation was to determine whether or not the radio therapeutic and diagnostic workers occupationally exposed to small doses of ionizing radiations daily, run a health risk? Results of cytogenetic analysis summarised here reveal a possible health effect, for the relevant frequency of dicentrics was high

Table 2: Chromosome aberrations among radiation workers and control groups with and without MMC treatment

\begin{tabular}{|c|c|c|c|c|c|c|c|c|c|c|}
\hline \multirow{3}{*}{$\begin{array}{l}\text { Subject } \\
\text { (treatment) }\end{array}$} & \multirow{3}{*}{$\begin{array}{l}\text { No. of } \\
\text { samples }\end{array}$} & \multirow{3}{*}{$\begin{array}{l}\text { No of } \\
\text { metaphases } \\
\text { scored }\end{array}$} & & \multicolumn{7}{|c|}{ Aberrations per 100 cells } \\
\hline & & & \multicolumn{4}{|c|}{ Chromosome-type } & \multicolumn{4}{|c|}{ Chromatid-type } \\
\hline & & & $\bar{G}$ & $B$ & $D$ & $R$ & $A F$ & $G$ & $B$ & $\overline{C I}$ \\
\hline Control & 12 & 1200 & 0.16 & 0.2 & 0.08 & - & - & 0.25 & 0.16 & - \\
\hline $\begin{array}{l}\text { Radiation } \\
\text { workers }\end{array}$ & 12 & 1200 & 1.16 & 0.66 & $1.08 *$ & 0.16 & 0.33 & $2.08 *$ & 1.66 & - \\
\hline $\begin{array}{c}\text { Control (MM } \\
10 \mathrm{ng} / \mathrm{ml}\end{array}$ & C) 12 & 1200 & 2 & 1.5 & 1.5 & 0.6 & 0.25 & 1.75 & 1 & 0.25 \\
\hline $\begin{array}{l}\text { Radiation } \\
\text { workers (M }\end{array}$ & $\mathrm{MC})^{12}$ & 1200 & 2.5 & 1.83 & $2.33 * *$ & $0.91 * *$ & 0.83 & 2.33 & 1.66 & $\begin{array}{c}0.33 \\
10 \mathrm{ng} / \mathrm{ml}\end{array}$ \\
\hline
\end{tabular}

G - Gap, B - Break, D - Dicentric, R - Ring, AF - Acentric fragment, CI - Chromatid interchange

* Significant at $(\mathrm{P}<0.05)$ as compared to control,

** Signficant at $(\mathrm{P}<0.05)$ as compared to MMC treated control

Table 3: Sister chromatid exchange and micronuclei frequency in control and radiation workers

\begin{tabular}{|c|c|c|c|c|c|c|c|c|c|c|}
\hline \multirow[t]{3}{*}{ Subject } & \multirow{3}{*}{$\begin{array}{c}\text { No. of } \\
\text { samples }\end{array}$} & \multirow{3}{*}{$\begin{array}{c}\text { No. of } \\
\text { M2 cells } \\
\text { scored }\end{array}$} & \multicolumn{5}{|c|}{ SCE frequency and replicative index } & \multicolumn{3}{|c|}{ Micronuclei frequency } \\
\hline & & & \multicolumn{3}{|c|}{$\begin{array}{c}\text { Percentage } \\
\text { of cells }\end{array}$} & \multirow[t]{2}{*}{$\begin{array}{c}\text { Mean } \\
\text { SCE/cell }\end{array}$} & \multirow[t]{2}{*}{$\begin{array}{l}\text { Replicative } \\
\text { index }\end{array}$} & \multirow{2}{*}{$\begin{array}{l}\text { No. of } \\
\text { BN cells } \\
\text { scored }\end{array}$} & \multirow[t]{2}{*}{$\begin{array}{l}\text { Total } \\
M N\end{array}$} & \multirow{2}{*}{$\begin{array}{c}\text { Mean } \\
\text { MN/ } \\
1000 \text { Cells }\end{array}$} \\
\hline & & & $M 1$ & $M 2$ & $M 3$ & & & & & \\
\hline Control & 12 & 360 & 45 & 32 & 23 & $2.32 \pm 0.08$ & 1.78 & 12000 & 110 & 9.16 \\
\hline $\begin{array}{l}\text { Radiation } \\
\text { Workers }\end{array}$ & 12 & 360 & 45 & 29 & 26 & $2.93 \pm 0.44$ & 1.81 & 12000 & 680 & $56.66^{*}$ \\
\hline
\end{tabular}

MN - Micronuclei, BN - Binucleated.

* Significant at $(\mathrm{P}<0.01)$ from control 
Table 4: Details of hematological parameters pooled from 12 control as well as 12 radiation workers

\begin{tabular}{llccc}
\hline No. & Parameters & Control & Radiation workers & Normal range $^{*}$ \\
\hline 1 & Hemoglobin (gm\%) & 13.33 & 14.02 & $12-18$ \\
2 & Total RBC (Million/cmm) & 4.25 & 4.65 & $4.2-6.2$ \\
3 & Total WBC (nos./cmm) & 7331 & 6800 & $4000-10500$ \\
4 & Total platelets (nos/cmm) & 233308 & 203000 & $150000-400000$ \\
\hline
\end{tabular}

*Normal range of hematological parameters as per Dietz, 1995 - Clinical guide to Laboratory tests.

among radiation workers as compared to control individuals.

Our results are consistent with the findings of Maddileti et al. (2002) who showed a significant increase in chromosomal aberrations among radiographers (worker exposed to X-rays) when compared to controls. Many other cytogentic studies (Jha and Sharma 1991; Kasuba et al. 1998; Hagelstrom et al. 1995) have similarly reported higher frequencies of CAs.

As far as we are aware, there are no reports available pertaining to the co- mutagenic/ synergistic effect of MMC on the occupationally exposed individuals. In the present study, in vitro treatment of $\mathrm{MMC}(1 \mathrm{O} \mathrm{ng} / \mathrm{ml}$.) brought about significant increase in dicentric and ring chromosomes among radiation workers as compared to controls. Result might suggest that radiation workers are more prone to clastogenic effects of MMC than does the controls. Sister chromatid exchange technique has been commonly employed to evaluate cytogenetic responses to chemical and radiation exposures; and is generally a more sensitive indicator of genotoxic risk than are structural aberrations (Tucker and Preston 1996) with such a consideration, SCE study was also undertaken. Our results revealed no significant change in either mean SCE frequency or replicative index among radiation workers in comparison to control group. On the other hand, Yadev and Seth (2000) reported a significant increase in the CAs and SCE in workers exposed to X-rays. Thierens et al. (2000) reported a high frequency of centromere positive and centromere negative micronuclei in the peripheral lymphocytes of hospital workers who were occupationally exposed to X-rays and gamma-rays. Recently, Maluf et al. (2001) reported an increased frequency of micronuclei and dicentric bridges in the lymphocytes of workers exposed to X-rays. Similarly in the present study there was significant increase in micronuclei frequency among radiation workers as compared to control. This could attribute to the higher frequency of chromosomal aberrations found among radiation workers. In addition results on in vitro gamma-irradiation of human lymphocytes confirmed a dose-dependent increase in micronuclei formation (Boreham et al. 2000) .

The hematological study revealed no significant change in the blood pictures of radiation workers when compared to controls. Probably, the parameters considered in the present study might not have been influenced much by low level irradiation.

In general the results of the present study indicate that; occupationally exposed radiation workers engaged in diagnostic and therapeutic applications of radiations, show increase in CAs as well as $\mathrm{MN}$ frequency, are more sensitive to mutagen MMC, but reveal no change in SCE frequency, RI or blood picture.

A preliminary indication of the present study is that long term low level radiation exposure may probably damage the genetic constitution of an individual. However, looking to the stringent small sample size, taken into account, no specific conclusion could be drawn.

\section{ACKNOWLEDGEMENTS}

We are thankful to Prof. Mahesh Vadel, Head, Department of Radiology, Government Medical College, Surat for his kind help. We are also thankful to radiation diagnostic and therapeutic workers in being volunteers for blood samples.

\section{REFERENCES}

Boreham DR, Dolling JA, Maves SR, Siwarungsan N, Mitchel REJ 2000. Dose rate effect for apoptosis and micronucleus formation in gamma-irradiated human lymphocytes. Radiat Res, 153(5): 579 586.

Cigarran S, Barquinero JF, Barrios L, Ribas M, Egozcue J, Caballin MR 2001. Cytogenetic analysis by Fluorescence in situ hybridization (FISH) in hospital workers occupationally exposed to low levels of ionizing radiations. Radiat Res, 155(3): 417-433. 
Evans HJ 1983. Effects on chromosome of carcinogenic ray and chemicals. In: James German (Ed.): Chromosome Mutation and Neoplasia. New York: Alan R. Liss, Inc. pp. 253 -279.

Fabry L, Lemaire M 1986. Dose response relationship for radiation induced chromosomal aberrations in human lymphocytes in vivo and in vitro. Strahlentherapie, 162: 63 -67.

Fenech M 1993. The cytokinesis block micronucleus technique. A detailed description of the method and its application to genotoxicity study in human population. Mutat Res, 285: 35 - 40.

Gadhia PK 1998. Possible age-dependent adapative response to a low dose of X-rays in human lymphocytes. Mutagenesis, 13(2): 151 - 152.

Hagelstrom AH, Gorla NB, Larripa IB 1995. Chromosomal damage in workers occupationally exposed to chronic low level ionizing radiation Toxicol Letters, 76(2): 113 - 117.

Hungerford DA 1965. Leucocytes cultured from small inocula of whole blood and preparations of metaphase chromosomes by treatment with hypotonic KCl. Stain Technol, 40: 333.

Jha AN, Sharma T 1991. Enhanced frequency of chromosome aberrations in workers occupationally exposed to diagnostic X -rays. Mutat Res, 260(4): $343-348$.

Kasuba V, Rozgaj R, Sentija K 1998. Chromosomal aberrations in medical staff occupationally exposed to X-rays: A follow up study. Arh Hig Rada Toksikol, 49(1): $1-8$

Lloyd DC, Lucas JN, Edwards AA, Deng W, Valente E, Hone PA, Moquet JE 2001. A study to verify a reported excess of chromosomal aberrations in blood lymphocytes of Namibian Uranium miner. Radiat Res, 155: $807-815$.

Maddileti U, Padmaja T, Hema Prasad M, Reddy PP 2002. Analysis of chromosomal aberrations in the peripheral lymphocytes of workers exposed to diagnostic X-rays. Int J Hum Genet, 2(3): 265 268

Maluf SW, Passor DF, Bacclar A, Speit G 2001.
Assessment of DNA damage in lymphocytes of workers exposed to X-radiation using the micronucleus test and comet assay. Environ Mol Mutagen, 38(4): $311-315$.

Milkovic-Kraus S, Kubelka D, Vekic B 1992. Biological monitoring of three cobalt-60 radiation incident victims. Am J Indust Med, 22: 243 - 247.

Natarajan AT, Vyas RC, Wiegant J, Curado MP 1991. A cytogenetic follow up study of the victims of radiation accident in Goiania (Brazil). Mutat Res, 247: $103-111$.

OSH-DB 1996. (Occupational Safety and Health Data base) Chromosome aberrations and rogue cells in lymphocytes of Chernobyl clean up workers. Mutat Res, 350(2): 315 - 329.

Pressl S, Stephan G 1998. Persistance of translocation detected by means of FISH in peripheral lymphocytes of accidentally exposed radiation workers. Radiat Protec Environ, 20(4): 170 - 173. Schevchekno VA, Akayeva EA, Yeliscyeva IN, Yellisova TV, Yofa EL, Nilova IN, Syomov AB, Burkart W 1996. Human cytogenetic consequencies of the Chernobyl accidents. Mutat Res, 361: 29 - 34

Thierens H, Vral A, Morthier R, Aoufalah B, DeRiddert 2000. Cytogenetic monitoring of hospital workers occupationally exposed to ionizing radiation using the micronucleus centromere assays. Mutagenesis, 15(3): 245 - 249.

Tucker JD, Preston RJ 1996. Chromosome aberrations, micronuclei, aneuploidy, sister chromatid exchanges and cancer risk assessment. Mutat Res, 365: 147 159.

Verdorfer I, Neubauer S, Letzel S, Angerer J, Arutyunyan R, Martus P, Wucherer M, Gebhart E 2001. Chromosome painting for cytogenetic monitoring of occupationally exposed and non-exposed groups of human individuals. Mutat Res, 491(1-2): 97 109.

Yadav JS, Seth N 2000.Effect of diagnostic X -rays on somatic chromosome of occupationally exposed workers. Ind J Exp Biol, 38(1): 46 - 50. 